Review Article

\title{
Inhibition of Myocardial Ischemia/Reperfusion Injury by Exosomes Secreted from Mesenchymal Stem Cells
}

\author{
Heng Zhang, Meng Xiang, Dan Meng, Ning Sun, and Sifeng Chen \\ Department of Physiology and Pathophysiology, Fudan University Shanghai Medical College, Shanghai 200032, China \\ Correspondence should be addressed to Sifeng Chen; chen1216@fudan.edu.cn
}

Received 24 January 2016; Accepted 29 March 2016

Academic Editor: Yaoliang Tang

Copyright ( 2016 Heng Zhang et al. This is an open access article distributed under the Creative Commons Attribution License, which permits unrestricted use, distribution, and reproduction in any medium, provided the original work is properly cited.

\begin{abstract}
Exosomes secreted by mesenchymal stem cells have shown great therapeutic potential in regenerative medicine. In this study, we performed meta-analysis to assess the clinical effectiveness of using exosomes in ischemia/reperfusion injury based on the reports published between January 2000 and September 2015 and indexed in the PUBMED and Web of Science databases. The effect of exosomes on heart function was evaluated according to the following parameters: the area at risk as a percentage of the left ventricle, infarct size as a percentage of the area at risk, infarct size as a percentage of the left ventricle, left ventricular ejection fraction, left ventricular fraction shortening, end-diastolic volume, and end-systolic volume. Our analysis indicated that the currently available evidence confirmed the therapeutic potential of mesenchymal stem cell-secreted exosomes in the improvement of heart function. However, further mechanistic studies, therapeutic safety, and clinical trials are required for optimization and validation of this approach to cardiac regeneration after ischemia/reperfusion injury.
\end{abstract}

\section{Introduction}

Given the limited regenerative captivity of heart cells, myocardial infarction has always been defined as irreversible disease, ultimately resulting in heart failure and death. Recently, it has been found that cardiac stem cells have a potential to differentiate into cardiomyocytes and vascular structures [1]. However, the number of these stem cells is too low to underwrite the restoration of severely impaired heart function. Several types of adult stem cells, including mesenchymal stem cells (MSCs), were used to treat myocardial infarction (MI) and produced optimistic results. It has been shown that the injection of MSCs derived from adult bone marrow into the area of infarction can reduce infarct size and restore heart function to some degree after ischemia/reperfusion injury $[2,3]$. Although the approach is very promising, there are risks associated with MSC application for cardiac regeneration, such as immunoreactivity and oncogenicity [4]. Accumulating evidence suggests that some of MSC therapeutic effects can be reproduced by MSCderived exosomes [5].

Exosomes are small membrane vesicles carrying DNA, RNAs, and proteins. They play important roles in cell-cell communication and interaction. The function of exosomes depends on cell origin of the exosomes. Mature dendritic cells (DCs) secrete exosomes that carry antigens which can induce antigen-specific immune responses in other DCs. Cho and colleagues [6] demonstrated that heat shock proteinsenriched exosomes can elicit antitumor responses in a MHCindependent manner. Exosomes released by melanoma cells prepare sentinel lymph nodes for tumor metastasis [7].

Stem cells are the most active and healthy cells. MSCs are a subset of adult stem cells that originate from the mesoderm. MSCs can easily be expanded ex vivo for a period of time without changing their characteristics. As described previously, MSCs have great potential in treating tissue injuries including myocardial infarction $[2,3]$, liver fibrosis [8], oxidative damage [9], and kidney injury [10]. MSCs of different tissue origin have similar therapeutic effects on myocardial injury [11-16]. The use of exosomes instead of the whole MSCs may circumvent the potential risks of MSC therapy. Therefore, therapeutic effects of MSCderived exosomes on ischemia/reperfusion heart injury have been explored in a number of animal models. Although most of the studies have demonstrated the therapeutic potential of exosomes isolated from MSCs, the effects showed certain 


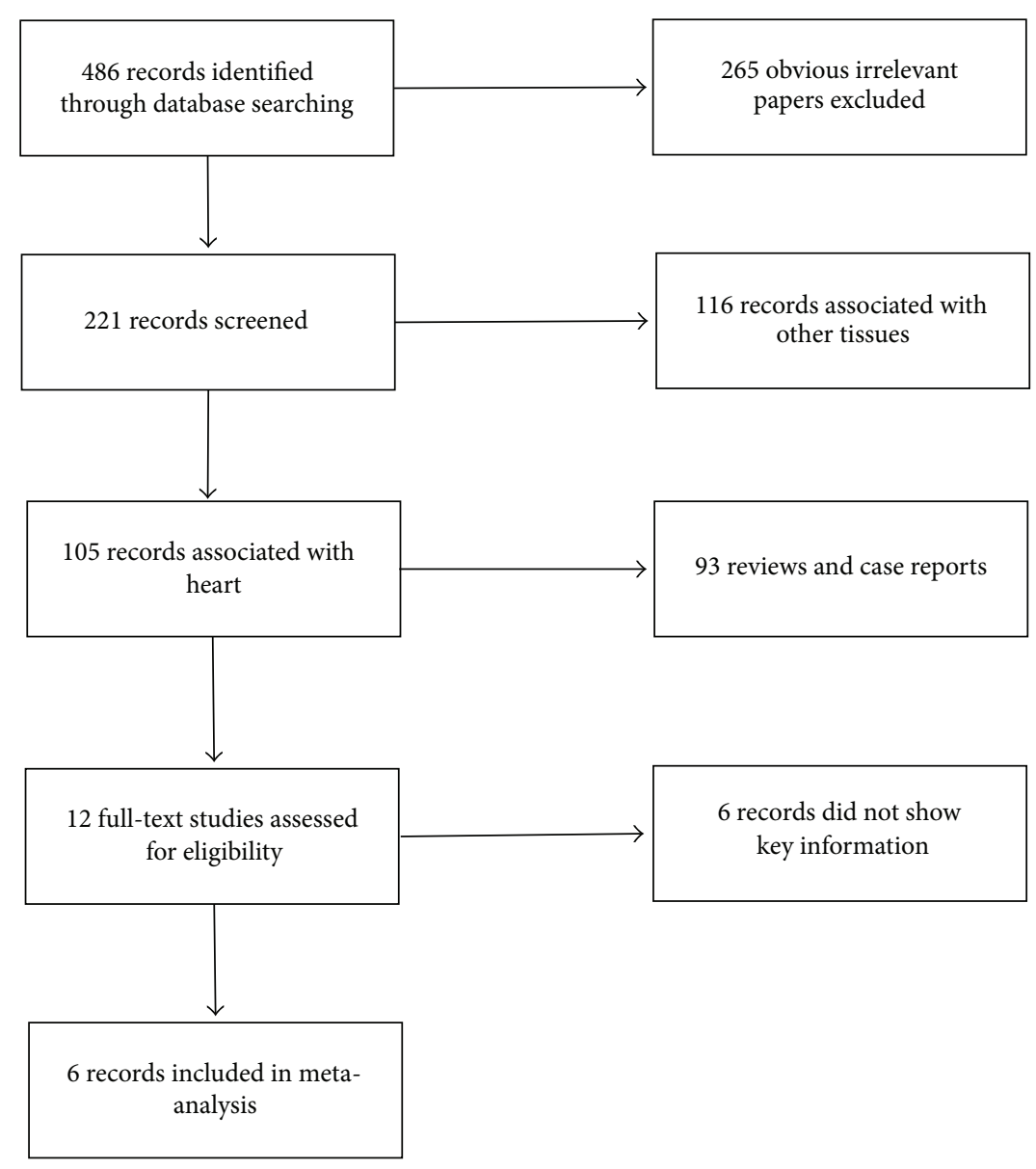

FIGURE 1: Results of systematic search of the literature.

variability, which raises some concerns about the clinical application of this treatment approach.

In this paper, we performed meta-analysis of the preclinical data obtained in six original research studies to verify the quality and strength of existing evidence on the therapeutic potential of MSC-isolated exosome [11-16]. Furthermore, we attempt to provide an updated assessment of regenerative effects exhibited by exosomes in ischemia/reperfusion heart injury.

\section{Methods}

2.1. Literature Search. Relevant papers published between January 2000 and September 2015 were screened in PUBMED and Web of Science databases using the following search terms: ("mesenchymal stem cell" OR "bone marrow stem cell") AND ("exosomes" OR “conditioned medium (CM)"). Language was limited in English. The online search strategy used is shown in Figure 1.

2.2. Inclusion and Exclusion Criteria. Studies meeting the following criteria at the same time were included in this paper: (1) animal model: myocardial ischemia/reperfusion; (2) therapy: use of exosomes derived from MSCs; (3) detailed information of heart function and structure which was shown in the studies. Articles meeting any of the following criteria were excluded: case report, editorial, or letter to editors; other meta-analysis; studies with no precise data.

2.3. Validated Terms. The following general study information was extracted: last name of first author, year of publication, country, race of animal, MI and surgical procedure, the type of MSCs used to extract exosomes, and the amount of exosomes injected. Secondly, to evaluate the effects of exosomes on heart function, the following data was extracted: AAR as a percentage of the left ventricle (AAR/LV), infarct size as a percentage of the area at risk (IS/AAR), infarct size as a percentage of left ventricle (IS/LV), left ventricular ejection fraction (EF), left ventricular fraction shortening (FS), enddiastolic volume (EDV), and end-systolic volume (ESV).

2.4. Statistical Analysis. The meta-analysis of data was analyzed using Stata (version 12.0) and Engauge Digitizer (version 4.1) was used to extract the data of graph.

\section{Results}

3.1. Studies Included. After searching the databases, a total of six articles were identified to be proper for our analysis. The detailed information of articles was shown in Table 1. 


\begin{tabular}{|c|c|c|c|c|c|c|}
\hline 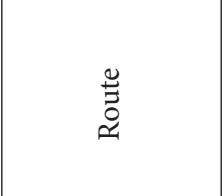 & 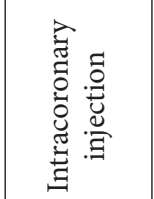 & 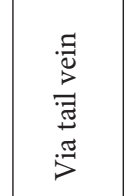 & 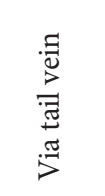 & 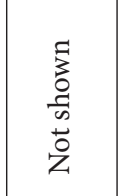 & 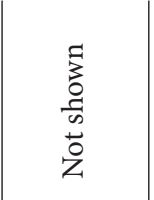 & 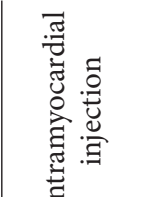 \\
\hline 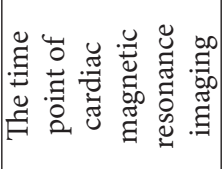 & 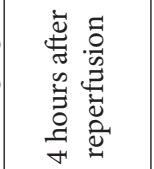 & ż & ż & 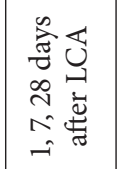 & 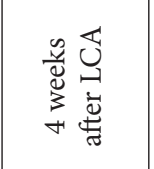 & 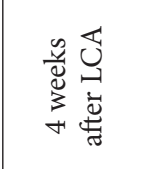 \\
\hline 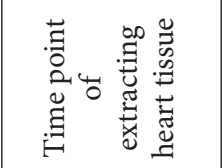 & 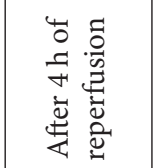 & 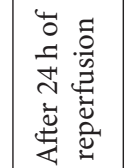 & 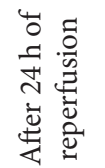 & 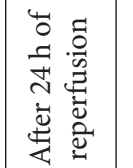 & 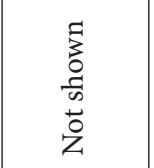 & $\begin{array}{l}\text { है } \\
\text { o } \\
\text { s } \\
\overrightarrow{0} \\
z\end{array}$ \\
\hline 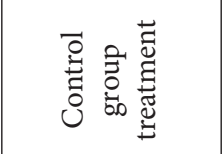 & 节 & 客: & 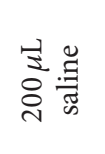 & 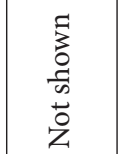 & 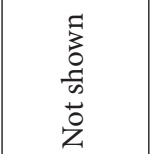 & 哥 \\
\hline 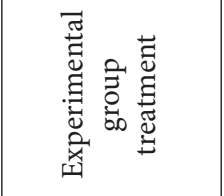 & 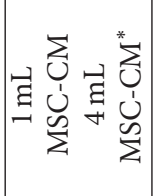 & 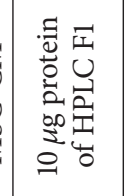 & 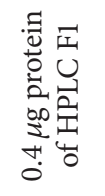 & 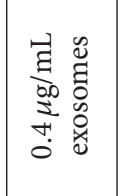 & 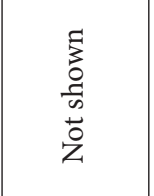 & 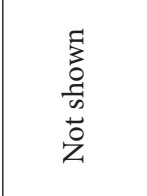 \\
\hline 冟 & 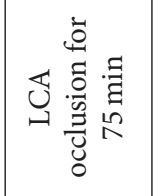 & 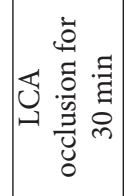 & 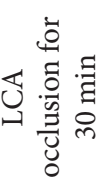 & 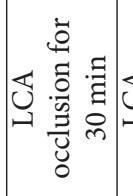 & 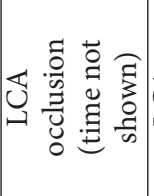 & 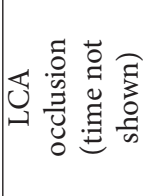 \\
\hline 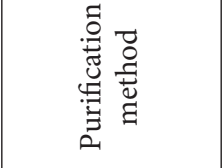 & $\begin{array}{l}\text { 岁 } \\
0 \\
\vdots \\
\vdots \\
\vdots\end{array}$ & 桼 & 莞 & $\begin{array}{l}0 \\
\dot{3} \\
\vdots\end{array}$ & 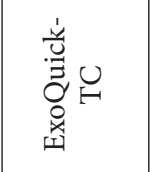 & $\begin{array}{l}8 \\
3 \\
\sum\end{array}$ \\
\hline$\frac{\mathscr{U}}{\mathscr{U}}$ & 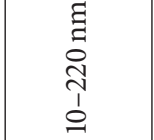 & $\begin{array}{l}\Xi \\
\vdots \\
0 \\
0 \\
1 \\
0 \\
\text { in }\end{array}$ & 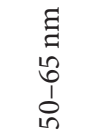 & 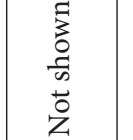 & $\begin{array}{l}\text { I } \\
\vdots \\
\stackrel{2}{a} \\
o \\
o\end{array}$ & 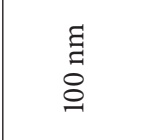 \\
\hline 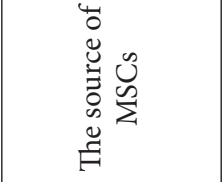 & Uي & 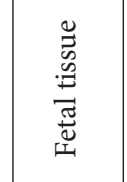 & 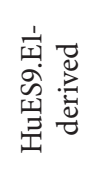 & 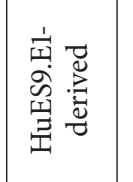 & 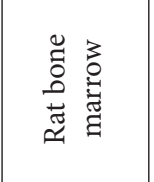 & 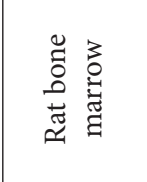 \\
\hline $\begin{array}{l}\text { 足 } \\
\text { 节 }\end{array}$ & .000 & $\begin{array}{l}\ddot{m} \\
\grave{z}\end{array}$ & 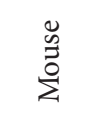 & $\begin{array}{l}\ddot{\mathscr{n}} \\
\tilde{\Xi} \\
\tilde{\Sigma}\end{array}$ & $\begin{array}{l}\vec{\Xi} \\
\simeq\end{array}$ & $\overrightarrow{\widetilde{E}}$ \\
\hline $\begin{array}{l}\hat{E} \\
\hat{\Xi}\end{array}$ & 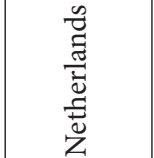 & 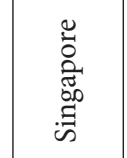 & $\begin{array}{l}\stackrel{0}{0} \\
\text { 㟧 } \\
: 0\end{array}$ & 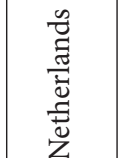 & 岕 & 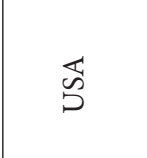 \\
\hline 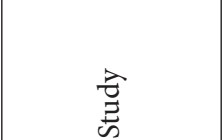 & 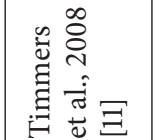 & 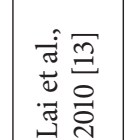 & 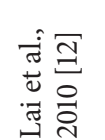 & 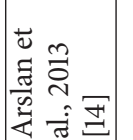 & 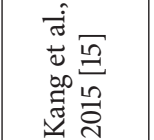 & 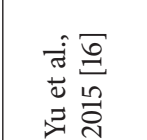 \\
\hline
\end{tabular}




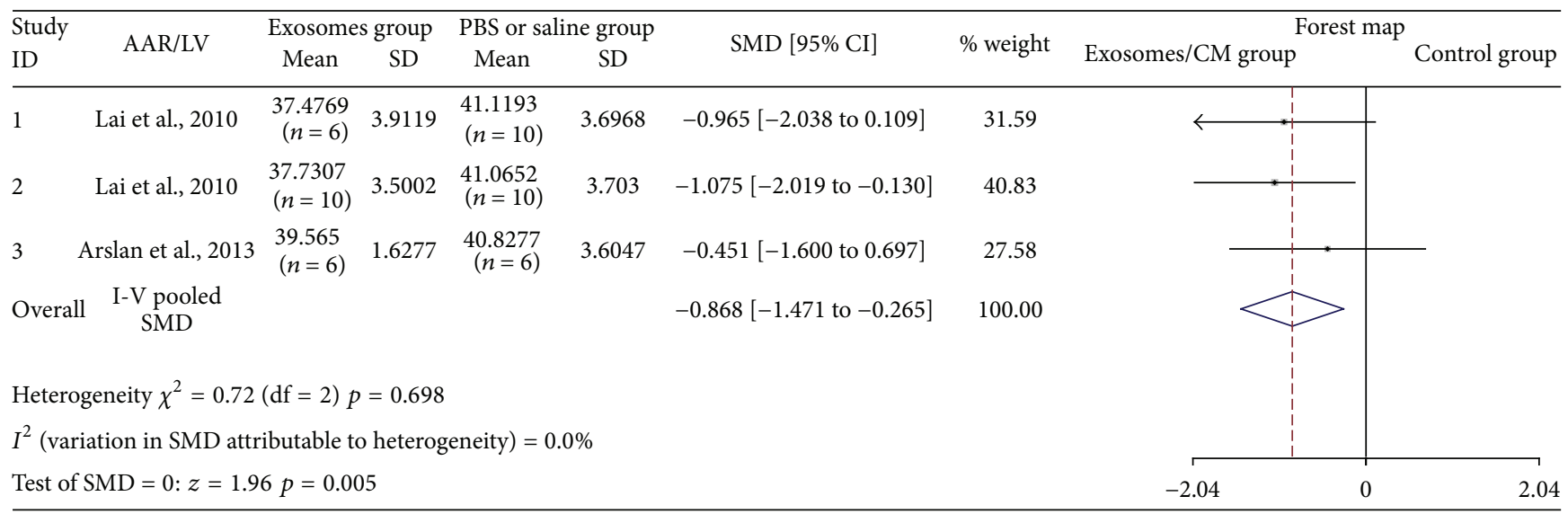

FIGURE 2: The effectiveness of exosomes on AAR/LV.

\begin{tabular}{|c|c|c|c|c|c|c|c|c|c|}
\hline \multirow{2}{*}{$\begin{array}{l}\text { Study } \\
\text { ID }\end{array}$} & \multirow{2}{*}{ IS/AAR } & \multicolumn{2}{|c|}{ Exosomes group } & \multicolumn{2}{|c|}{ PBS or saline group } & \multirow{2}{*}{ SMD $[95 \% \mathrm{CI}]$} & \multirow{2}{*}{$\%$ weight } & \multicolumn{2}{|c|}{ Forest map } \\
\hline & & Mean & SD & Mean & SD & & & Exosomes/CM group & Control group \\
\hline 1 & Timmers et al., 2008 & $\begin{array}{r}25.7441 \\
(n=9)\end{array}$ & 4.6546 & $\begin{array}{c}63.3693 \\
(n=8)\end{array}$ & 8.1467 & $-5.770[-8.043$ to -3.496$]$ & 27.82 & & \\
\hline 2 & Lai et al., 2010 & $\begin{array}{c}18.6462 \\
(n=6)\end{array}$ & 2.211 & $\begin{array}{l}34.3895 \\
(n=10)\end{array}$ & 2.91 & $-5.871[-8.270$ to -3.473$]$ & 25.00 & & \\
\hline 3 & Lai et al., 2010 & $\begin{array}{l}17.2613 \\
(n=10)\end{array}$ & 3.3105 & $\begin{array}{l}34.6493 \\
(n=10)\end{array}$ & 3.306 & $-5.265[-7.184$ to -3.328$]$ & 38.71 & & \\
\hline 4 & Arslan et al., 2013 & $\begin{array}{c}21.3194 \\
(n=6)\end{array}$ & 2.1812 & $\begin{array}{l}38.7478 \\
(n=6)\end{array}$ & 1.6364 & $-9.039[-13.159$ to -4.919$]$ & 8.47 & & \\
\hline Overa & all $\begin{array}{c}\mathrm{I}-\mathrm{V} \text { pooled } \\
\text { SMD }\end{array}$ & & & & & $-5.873[-7.073$ to -4.674$]$ & 100.00 & & \\
\hline \multicolumn{10}{|c|}{ Heterogeneity $\chi^{2}=2.67(\mathrm{df}=3) p=0.445$} \\
\hline \multicolumn{8}{|c|}{$I^{2}($ variation in SMD attributable to heterogeneity $)=0.00 \%$} & -13.2 & 13.2 \\
\hline
\end{tabular}

FIGURE 3: The effectiveness of exosomes on IS/AAR.

All articles chosen were published between 2008 and 2015, with two performed in the USA, two in Singapore, and two in Netherlands. Additional details not shown in Table 1 should be noted. Thus, in one study, animals were injected with CM twice (first $5 \mathrm{~min}$ prior to the onset of reperfusion and second immediately following reperfusion) [11], while in two studies, both HPLC-purified exosomes and CM were utilized in the experiments $[12,13]$. In this analysis, we used only the data on purified exosomes. Other two studies compared the effect of the wild-type and genetically modified exosomes $[15,16]$; however, we used only the data related to the wild-type exosomes to exclude the therapeutic effect of protein overexpression on MI. In one publication, we extracted the data on the effect of exosomes used at the concentration of $16 \mu \mathrm{g} / \mathrm{kg}$ [14].

3.2. The Effectiveness of Exosomes on $A A R / L V$. Three studies assessed AAR/LV after injection of exosomes [11, 12, 14]. Forty-eight animal cases (22 cases in experimental group; 26 cases in control group) were included. Generally, exosomesbased therapy was associated with mild AAR/LV reduction (SMD: $-0.868,95 \%$ CI: -1.471 to $-0.265, p=0.005$ ); heterogeneity was not observed $\left(I^{2}=0.0 \%, p=0.698\right)$ (Figure 2). All articles showed similar AAR/LV decreasing trend in exosomes groups.
3.3. The Effectiveness of Exosomes on IS/AAR. Four studies assessed IS/AAR after injection of exosomes [11-14]. Sixtyfive animal cases (31 cases in experimental group; 34 cases in control group) were included. Generally, exosomes therapy was associated with significantly lower IS/AAR (SMD: $-5.873,95 \%$ CI: -7.073 to $-4.674, p<0.0001)$. Heterogeneity was observed $\left(I^{2}=0.0 \%, p=0.445\right)$ (Figure 3 ). All articles reported similar IS/AAR decreasing trend in exosomes groups.

3.4. The Effectiveness of Exosomes on $I S / L V$. Two studies assessed IS/LV after injection of exosomes [11, 15]. Twentynine animal cases (15 cases in experimental group; 14 cases in control group) were included. Generally, the effect of exosomes therapy was associated with IS/LV reduction (SMD: $-3.830,95 \%$ CI: -5.162 to $-2.497, p=0.002)$. Heterogeneity was not observed $\left(I^{2}=71.7 \%, p=0.06\right.$ ) (Figure 4$)$. All articles showed similar trend in exosomes groups.

3.5. The Effectiveness of Exosomes on EF Group. Four studies assessed EF after injection of exosomes [11, 14-16]. Seventyone animal cases (40 cases in experimental group; 31 cases in control group) were included. Generally, the effect of exosomes therapy on upregulating EF was significant (SMD: 


\begin{tabular}{|c|c|c|c|c|c|c|c|c|c|}
\hline \multirow{2}{*}{$\begin{array}{l}\text { Study } \\
\text { ID }\end{array}$} & \multirow{2}{*}{ IS/LV } & \multicolumn{2}{|c|}{ Exosomes group } & \multicolumn{2}{|c|}{ PBS or saline group } & \multirow{2}{*}{ SMD $[95 \% \mathrm{CI}]$} & \multirow{2}{*}{$\%$ weight } & \multicolumn{2}{|c|}{ Forest map } \\
\hline & & Mean & SD & Mean & SD & & & Exosomes/CM group & Control group \\
\hline 1 & Kang et al., 2015 & $\begin{array}{c}38.2822 \\
(n=6)\end{array}$ & 2.9448 & $\begin{array}{l}48.9571 \\
(n=6)\end{array}$ & 4.4171 & $-2.844[-4.527$ to -1.160$]$ & 62.68 & & \\
\hline 2 Tir & immers et al., 2008 & $\begin{array}{c}7.6 \\
(n=9)\end{array}$ & 1.4 & $\begin{array}{c}20.5 \\
(n=8)\end{array}$ & 3.1 & $-5.486[-7.667$ to -3.304$]$ & 37.32 & & \\
\hline Overal & all $\begin{array}{c}\mathrm{I}-\mathrm{V} \text { pooled } \\
\text { SMD }\end{array}$ & & & & & $-3.830[-5.162$ to -2.497$]$ & 100.00 & & \\
\hline \multicolumn{10}{|c|}{ Heterogeneity $\chi^{2}=3.53(\mathrm{df}=1) p=0.060$} \\
\hline \multicolumn{8}{|c|}{ Estimate of between-study variance $\tau^{2}=2.5014$} & & \\
\hline \multicolumn{8}{|c|}{ Test of SMD $=0: z=3.09, p=0.002$} & 7.67 & 7.67 \\
\hline
\end{tabular}

FIgURE 4: The effectiveness of exosomes on IS/LV.

\begin{tabular}{|c|c|c|c|c|c|c|c|c|c|c|}
\hline \multirow{2}{*}{$\begin{array}{l}\text { Study } \\
\text { ID }\end{array}$} & \multirow{2}{*}{$\mathrm{EF}$} & \multicolumn{2}{|c|}{ Exosomes group } & \multicolumn{2}{|c|}{ PBS or saline group } & \multirow{2}{*}{ SMD $[95 \% \mathrm{CI}]$} & \multirow{2}{*}{$\%$ weight } & \multicolumn{3}{|c|}{ Forest map } \\
\hline & & Mean & $\mathrm{SD}$ & Mean & $\mathrm{SD}$ & & & Exosomes/CM group & & Control group \\
\hline 1 & Timmers et al., 2008 & $\begin{array}{c}54.2 \\
(n=9)\end{array}$ & 2.6 & $\begin{array}{c}34.7 \\
(n=8)\end{array}$ & 4.4 & $-5.311[-7.437$ to -3.185$]$ & 10.96 & & $\rightarrow$ & \\
\hline 2 & Arslan et al., 2013 & $\begin{array}{l}53.5003 \\
(n=10)\end{array}$ & 1 & $\begin{array}{c}35.8412 \\
(n=6)\end{array}$ & 1 & $17.659[11.040$ to 24.278$]$ & 1.13 & & & \\
\hline 3 & Kang et al., 2015 & $\begin{array}{c}46.7084 \\
(n=6)\end{array}$ & 3.0656 & $\begin{array}{c}31.7166 \\
(n=6)\end{array}$ & 3.0612 & $4.849[2.469$ to 7.319$]$ & 8.42 & & $\rightarrow$ & \\
\hline 4 & Yu et al., 2015 & $\begin{array}{c}46.8 \\
(n=15)\end{array}$ & 3.2 & $\begin{array}{c}34.4 \\
(n=11)\end{array}$ & 2.2935 & $0.471[-0.299$ to 1.261$]$ & 79.49 & & & \\
\hline Overal & all $\begin{array}{c}\mathrm{I}-\mathrm{V} \text { pooled } \\
\text { SMD }\end{array}$ & & & & & $1.556[0.860$ to 2.272$]$ & 100.00 & & $\Delta$ & \\
\hline \multicolumn{11}{|c|}{ Heterogeneity $\chi^{2}=49.73(\mathrm{df}=3) p<0.0001$} \\
\hline \multicolumn{11}{|c|}{$I^{2}$ (variation in SMD attributable to heterogeneity) $=94 \%$} \\
\hline \multicolumn{8}{|c|}{ Test of SMD $=0: z=4.35, p<0.0001$} & -24.3 & & 24.3 \\
\hline
\end{tabular}

FIgURE 5: The effectiveness of exosomes on EF.

1.566, 95\% CI: 0.860 to $1.261, p<0.0001)$. However, certain heterogeneity was observed $\left(I^{2}=94 \%, p<0.0001\right)$ (Figure 5). While all studies demonstrated EF increase in the exosome-treated group, the increase of EF observed by Arslan et al. was significantly higher than others'. If this study was excluded, heterogeneity would decrease to an insignificant level.

3.6. The Effectiveness of Exosomes on FS. Three studies assessed FS after injection of exosomes [11, 15, 16]. Fiftyfive animal cases (30 cases in experimental group; 25 cases in control group) were included. Generally, the effect of exosomes therapy on upregulating FS was significant (SMD: 3.413, 95\% CI: 2.484 to 4.343, $p<0.0001$ ) (Figure 6). Though all studies showed FS increase in the exosometreated animals, the findings showed inconsistency, resulting in significant heterogeneity $\left(I^{2}=86.2 \%, p=0.001\right)$.

3.7. The Effectiveness of Exosomes on EDV. Three studies assessed EDV after injection of exosomes [11, 14, 16]. Fifty-five animal cases ( 30 cases in experimental group; 25 cases in control group) were included. Generally, the effect of exosomes was associated with EDV reduction (SMD: $-0.861,95 \% \mathrm{CI}$ :
-1.514 to $-0.209, p=0.01$ ) (Figure 7 ). However, Timmers et al. [11] have reported that EDV decrease by exosomes therapy was statistically insignificant, which resulted in heterogeneity among the analyzed data $\left(I^{2}=94 \%, p<0.0001\right)$.

3.8. The Effectiveness of Exosomes on ESV. Three studies assessed ESV after injection of exosomes [11, 14, 16]. Fiftynine animal cases (34 cases in experimental group; 25 cases in control group) were included. Generally, the effect of exosomes therapy on lowering ESV was significant (SMD: $-2.682,95 \%$ CI: -3.492 to $-1.872, p<0.0001$ ) (Figure 8); however, although ESV reduction trend in the exosomestreated groups was consistent among the studies, considerable heterogeneity was observed $\left(I^{2}=90.4 \%, p<0.0001\right)$. Thus, the effect detected by Arslan et al. was markedly higher than that reported in the other two articles that demonstrated no heterogeneity.

\section{Discussion}

Myocardial infarction and associated complication are a great socioeconomic burden to healthcare system. Stem cells including MSCs therapy could be promising approach in 


\begin{tabular}{|c|c|c|c|c|c|c|c|c|c|c|}
\hline \multirow{2}{*}{$\begin{array}{l}\text { Study } \\
\text { ID }\end{array}$} & \multirow{2}{*}{ FS } & \multicolumn{4}{|c|}{ Exosomes group PBS or saline group } & \multirow{2}{*}{ SMD $[95 \% \mathrm{CI}]$} & \multirow{2}{*}{$\%$ weight } & \multicolumn{3}{|c|}{ Forest map } \\
\hline & & Mean & SD & Mean & SD & & & Exosomes/CM group & & Control group \\
\hline 1 & Kang et al., 2015 & $\begin{array}{c}21.3651 \\
(n=6)\end{array}$ & 2.3463 & $\begin{array}{c}14.8393 \\
(n=6)\end{array}$ & 4.0209 & $1.982[0.556$ to 3.409$]$ & 42.49 & & $\rightarrow 1$ & \\
\hline 2 & Timmers et al., 2008 & $8 \begin{array}{c}36.5 \\
(n=9)\end{array}$ & 2 & $\begin{array}{c}21.7 \\
(n=8)\end{array}$ & 1.2 & $8.836[5.534$ to 12.139$]$ & 7.93 & & & \\
\hline 3 & Yu et al., 2015 & $\begin{array}{l}20.4739 \\
(n=15)\end{array}$ & 2.0013 & $\begin{array}{l}14.5253 \\
(n=11)\end{array}$ & 0.6 & $3.773[2.452$ to 5.093$]$ & 49.58 & & & \\
\hline Overal & $\begin{array}{c}\text { I-V pooled } \\
\text { SMD }\end{array}$ & & & & & $3.413[2.484$ to 4.343$]$ & 100.00 & & & \\
\hline \multicolumn{11}{|c|}{ Heterogeneity $\chi^{2}=14.51(\mathrm{df}=2) p=0.001$} \\
\hline \multicolumn{11}{|c|}{$I^{2}($ variation in SMD attributable to heterogeneity $)=86.2 \%$} \\
\hline \multicolumn{6}{|c|}{ Test of SMD $=0: z=7.19, p<0.0001$} & & & 2.1 & 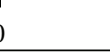 & 12.1 \\
\hline
\end{tabular}

FIgURE 6: The effectiveness of exosomes on FS.

\begin{tabular}{|c|c|c|c|c|c|c|c|c|c|}
\hline \multirow{2}{*}{$\begin{array}{l}\text { Study } \\
\text { ID }\end{array}$} & \multirow{2}{*}{ EDV } & \multicolumn{2}{|c|}{ Exosomes group } & \multicolumn{2}{|c|}{ Saline group } & \multirow{2}{*}{ SMD $[95 \% \mathrm{CI}]$} & \multirow{2}{*}{$\%$ weight } & \multicolumn{2}{|c|}{ Forest map } \\
\hline & & Mean & SD & Mean & $\mathrm{SD}$ & & & Exosomes/CM group & Control group \\
\hline T & Timmers et al., 2008 & $8 \begin{array}{c}69.7 \\
(n=9)\end{array}$ & 1 & $\begin{array}{c}69.1 \\
(n=8)\end{array}$ & 3.697 & $0.228[0.728$ to 1.184$]$ & 46.60 & & \\
\hline 2 & Arslan et al., 2013 & $\begin{array}{l}57.9325 \\
(n=10)\end{array}$ & 1 & $\begin{array}{c}81.2551 \\
(n=6)\end{array}$ & 1 & $-23.323[-32.020$ to -14.625$]$ & 0.56 & $\cdot$ & \\
\hline 3 & Yu et al., 2015 & $\begin{array}{c}1.6586 \\
(n=15)\end{array}$ & 0.2149 & $\begin{array}{c}1.9763 \\
(n=11)\end{array}$ & 0.1201 & $-1.582[-2.480$ to 0.685$]$ & 52.84 & & \\
\hline Overal & all $\begin{array}{c}\mathrm{I}-\mathrm{V} \text { pooled } \\
\text { SMD }\end{array}$ & & & & & $-0.861[-1.514$ to -0.209$]$ & 100.00 & & \\
\hline \multicolumn{10}{|c|}{ Heterogeneity $\chi^{2}=33.09(\mathrm{df}=2) p<0.0001$} \\
\hline \multicolumn{10}{|c|}{$I^{2}$ (variation in SMD attributable to heterogeneity) $=94 \%$} \\
\hline \multicolumn{8}{|c|}{ Test of SMD $=0: z=2.59, p=0.010$} & -32 & 32 \\
\hline
\end{tabular}

FIgUrE 7: The effectiveness of exosomes on EDV.

\begin{tabular}{|c|c|c|c|c|c|c|c|c|c|}
\hline \multirow{2}{*}{$\begin{array}{l}\text { Study } \\
\text { ID }\end{array}$} & \multirow{2}{*}{ ESV } & \multicolumn{2}{|c|}{ Exosomes group } & \multicolumn{2}{|c|}{ PBS or saline group } & \multirow{2}{*}{ SMD $[95 \% \mathrm{CI}]$} & \multirow{2}{*}{$\%$ weight } & \multicolumn{2}{|c|}{ Forest map } \\
\hline & & Mean & $\mathrm{SD}$ & Mean & SD & & & Exosomes/CM group & Control group \\
\hline 1 & Timmers et al., 2008 & $\begin{array}{c}31.4 \\
(n=9)\end{array}$ & 1.4 & $\begin{array}{c}47.5 \\
(n=8)\end{array}$ & 9.6 & $-2.426[-3.714$ to -1.137$]$ & 39.54 & & \\
\hline 2 & Arslan et al., 2013 & $\begin{array}{l}25.5948 \\
(n=10)\end{array}$ & 1 & $\begin{array}{l}45.3604 \\
(n=6)\end{array}$ & 1 & $-19.766[27.156$ to -12.375$]$ & 1.20 & $\longrightarrow$ & \\
\hline 3 & Yu et al., 2015 & $\begin{array}{c}0.9473 \\
(n=15)\end{array}$ & 0.1686 & $\begin{array}{c}1.3057 \\
(n=11)\end{array}$ & 0.0963 & $-2.506[-3.559$ to -1.454$]$ & 59.25 & & \\
\hline Overa & all $\begin{array}{c}\mathrm{I}-\mathrm{V} \text { pooled } \\
\text { SMD }\end{array}$ & & & & & $-2.682[-3.492$ to -1.872$]$ & 100.00 & & \\
\hline \multicolumn{10}{|c|}{ Heterogeneity $\chi^{2}=20.78(\mathrm{df}=2) p<0.0001$} \\
\hline \multicolumn{10}{|c|}{$I^{2}($ variation in SMD attributable to heterogeneity $)=90.4 \%$} \\
\hline \multicolumn{8}{|c|}{ Test of SMD $=0: z=6.49, p<0.0001$} & -27.2 & 27.2 \\
\hline
\end{tabular}

Figure 8: The effectiveness of exosomes on ESV.

curing patients with MI. Moreover, there is accumulating evidence that stem cell-secreted products could be used to treat MI-caused injuries [17, 18]. However, our search of the PUBMED and Web of Science was to find out that only one systematic review about the effects of microvesicle therapy on MI has been published in 2015 [19]. Although the systematic review included four articles related to therapy of exosomes or CM on MI injury, they reported only one clinical parameter (AAR), which is insufficient to make conclusions about the therapeutic potential of exosomes. In fact, there are 12 control trials published in 2008 to 2015 providing new evidence (unfortunately, six of them did not show the 
key information; we had to delete them). Thus, an updated meta-analysis is crucial. This meta-analysis is based on six controlled preclinical trials to demonstrate that exosomes or CM therapy could significantly improve heart function, in terms of IS/AAR, AAR/LV, IS/LV, EF, FS, EDV, and ESV.

In the mid-1980s, Johnstone [20] firstly reported that reticulocytes released the bulk of their transferrin receptor in association with small membrane vesicles. The exocytosed vesicles were uncovered after ultracentrifugation at $100,000 \times \mathrm{g}$ for $90 \mathrm{~min}$ and were named exosome. Exosomes are bilipid membrane particles with a diameter of 50-100 nm. They carry various proteins and RNA to effect numerous pathways. Several studies reported that exosome was the key signal in cell-cell interaction. There is accumulating evidence that cells may transiently modify the phenotype of neighboring cells by proteins and RNAs through mechanism that involves exosomes [21]. Some of biological active components of MVs depend on the cell of origin. Microvesicle(MV-) mediated exchange of receptors, proteins, mRNA, and miRNA between therapeutic cells and cells in damaged organs for MV delivering could temporally modify the phenotypes of these cells. Components of exosomes membrane, for example, sphingosine-1-phosphate (SIP), inhibit cell apoptosis and stimulate angiogenesis. The exosomes derived from MSCs have cardioprotective effects confirmed by some studies. Embryo stem cell-derived MVs can induce phosphorylation of MAPK p42/44 and serine-threonine kinase AKT [21]. Arslan et al. [14] demonstrated that exosomes can replenish depleted glycolytic enzymes to raise the level of ATP and NADH in the heart. Subsequently, they found out that exosomes derived from MSCs can manifestly increase AKT and GSK3 phosphorylation. Besides, proapoptotic phosphorylation of c-JNK was reduced. Based on these findings, the author concluded that exosomes can increase ATP levels and decrease oxidative stress and activated PI3K/Akt pathway to exert cardioprotective effects.

In IS/AAR group, Timmers et al. [11, 13, 14] all confirmed that hESE-MSC secretion reduces infarct size in mouse and pigs MI/R injury model. Though Timmers et al. used pigs as animal model, the meta-analysis showed positive results: IS/AAR was significantly decreased and heterogeneity was not observed, indicating that exosomes showed consistent therapeutic potential in reducing IS/AAR. Similar consistency was detected after the analysis of exosomes effects on AAR/LV and IS/LV [11-14].

However, in the parameters of heart function groups (EF, FS, EDV, and ESV), although heart function had been improved to some extent, the heterogeneity was observed and significant. For example, the data on ESV, EDV, and EF provided by Arslan et al. [14] was markedly higher than other studies' data. Arslan et al. [14] did not give the exact dose of exosome injected. Nor did they give the way of injection. This fact made us speculate that they may give more dose of exosomes or find a more effective way to inject the exosomes. On the other hand, the data on ESV and EDV provided by Yu et al. [16] was significantly lower than others' results. Yu et al. [16] did not give the precise dose of exosomes used either.

The current research has some limitations. First, the number of trials was relatively small. Second, the seven parameters we chose are not enough to show the whole function of exosomes. Third, the data of heart function parameters was not consistent causing the heterogeneity. Fourth, not all the articles gave the specific details we needed. Fifth, we acknowledge that the analysis may present a bias towards overestimation of positive outcomes, since negative results are less likely to be published. The relative homogeneity of this analysis is in certain contrast to the heterogeneity in clinical studies. Finally, we also should be reminded that none of the studies reviewed here mentioned potential serious adverse effects on other tissues; therefore, the safety of the exosome therapy is still unclear [19].

\section{Conclusions}

Based on the published evidence, our meta-analysis presented a novel insight of the therapeutic effect of MSCderived exosomes on MI. The preclinical results are encouraging for preparing and using feasibility studies in humans. We believed that further studies are required to validate the therapeutic safety in the future although the researchers did not find the side effect of exosomes derived from MSCs in animals. Validation of optimal conditions for their clinical application is also needed.

\section{Competing Interests}

The authors declare that they have no competing interests.

\section{Acknowledgments}

This work was supported by the Great International Cooperation Program (81220108002 to Sifeng Chen), Key Programs (30830050 to Sifeng Chen), Great Program (91539120 to Sifeng Chen), and General Program (81170298 and 81270410 to Dan Meng and 81100047 to Meng Xiang) of the National Natural Science Foundation of China.

\section{References}

[1] K. E. Hatzistergos, H. Quevedo, B. N. Oskouei et al., "Bone marrow mesenchymal stem cells stimulate cardiac stem cell proliferation and differentiation," Circulation Research, vol. 107, no. 7, pp. 913-922, 2010.

[2] P. Menasché, A. A. Hagège, J.-T. Vilquin et al., "Autologous skeletal myoblast transplantation for severe postinfarction left ventricular dysfunction," Journal of the American College of Cardiology, vol. 41, no. 7, pp. 1078-1083, 2003.

[3] E. C. Perin, H. F. R. Dohmann, R. Borojevic et al., "Transendocardial, autologous bone marrow cell transplantation for severe, chronic ischemic heart failure," Circulation, vol. 107, no. 18, pp. 2294-2302, 2003.

[4] J. Tolar, A. J. Nauta, M. J. Osborn et al., "Sarcoma derived from cultured mesenchymal stem cells," STEM CELLS, vol. 25, no. 2, pp. 371-379, 2007.

[5] M. Gnecchi, Z. Zhang, A. Ni, and V. J. Dzau, "Paracrine mechanisms in adult stem cell signaling and therapy," Circulation Research, vol. 103, no. 11, pp. 1204-1219, 2008.

[6] J.-A. Cho, Y.-S. Lee, S.-H. Kim, J.-K. Ko, and C.-W. Kim, "MHC independent anti-tumor immune responses induced by 
Hsp70-enriched exosomes generate tumor regression in murine models," Cancer Letters, vol. 275, no. 2, pp. 256-265, 2009.

[7] J. L. Hood, R. S. Sa, and S. A. Wickline, "Exosomes released by melanoma cells prepare sentinel lymph nodes for tumor metastasis," Cancer Research, vol. 71, no. 11, pp. 3792-3801, 2011.

[8] T. Li, Y. Yan, B. Wang et al., "Exosomes derived from human umbilical cord mesenchymal stem cells alleviate liver fibrosis," Stem Cells and Development, vol. 22, no. 6, pp. 845-854, 2013.

[9] Y. Zhou, H. Xu, W. Xu et al., "Exosomes released by human umbilical cord mesenchymal stem cells protect against cisplatin-induced renal oxidative stress and apoptosis in vivo and in vitro," Stem Cell Research and Therapy, vol. 4, article 34, 2013.

[10] A. Dorronsoro and P. D. Robbins, "Regenerating the injured kidney with human umbilical cord mesenchymal stem cellderived exosomes," Stem Cell Research \& Therapy, vol. 4, no. 2, article 39, 2013.

[11] L. Timmers, S. K. Lim, F. Arslan et al., "Reduction of myocardial infarct size by human mesenchymal stem cell conditioned medium," Stem Cell Research, vol. 1, no. 2, pp. 129-137, 2008.

[12] R. C. Lai, F. Arslan, M. M. Lee et al., "Exosome secreted by MSC reduces myocardial ischemia/reperfusion injury," Stem Cell Research, vol. 4, no. 3, pp. 214-222, 2010.

[13] R. C. Lai, F. Arslan, S. S. Tan et al., "Derivation and characterization of human fetal MSCs: an alternative cell source for largescale production of cardioprotective microparticles," Journal of Molecular and Cellular Cardiology, vol. 48, no. 6, pp. 1215-1224, 2010.

[14] F. Arslan, R. C. Lai, M. B. Smeets et al., "Mesenchymal stem cell-derived exosomes increase ATP levels, decrease oxidative stress and activate PI3K/Akt pathway to enhance myocardial viability and prevent adverse remodeling after myocardial ischemia/reperfusion injury," Stem Cell Research, vol. 10, no. 3, pp. 301-312, 2013.

[15] K. Kang, R. Ma, W. Cai et al., "Exosomes secreted from CXCR4 overexpressing mesenchymal stem cells promote cardioprotection via akt signaling pathway following myocardial infarction," Stem Cells International, vol. 2015, Article ID 659890, 14 pages, 2015.

[16] B. Yu, H. W. Kim, M. Gong et al., "Exosomes secreted from GATA-4 overexpressing mesenchymal stem cells serve as a reservoir of anti-apoptotic microRNAs for cardioprotection," International Journal of Cardiology, vol. 182, pp. 349-360, 2015.

[17] Y. Zhao, X. Sun, W. Cao et al., "Exosomes derived from human umbilical cord mesenchymal stem cells relieve acute myocardial ischemic injury," Stem Cells International, vol. 2015, Article ID 761643, 12 pages, 2015.

[18] Y. Feng, W. Huang, M. Wani, X. Yu, and M. Ashraf, "Ischemic preconditioning potentiates the protective effect of stem cells through secretion of exosomes by targeting Mecp2 via miR-22," PLoS ONE, vol. 9, no. 2, Article ID e88685, 2014.

[19] C. Akyurekli, Y. Le, R. B. Richardson, D. Fergusson, J. Tay, and D. S. Allan, "A systematic review of preclinical studies on the therapeutic potential of mesenchymal stromal cell-derived microvesicles," Stem Cell Reviews and Reports, vol. 11, no. 1, pp. 150-160, 2015.

[20] R. M. Johnstone, "The Jeanne Manery-Fisher Memorial Lecture 1991. Maturation of reticulocytes: formation of exosomes as a mechanism for shedding membrane proteins," Biochemistry and Cell Biology, vol. 70, no. 3-4, pp. 179-190, 1992.
[21] J. Ratajczak, M. Wysoczynski, F. Hayek, A. Janowska-Wieczorek, and M. Z. Ratajczak, "Membrane-derived microvesicles: important and underappreciated mediators of cell-to-cell communication," Leukemia, vol. 20, no. 9, pp. 1487-1495, 2006. 

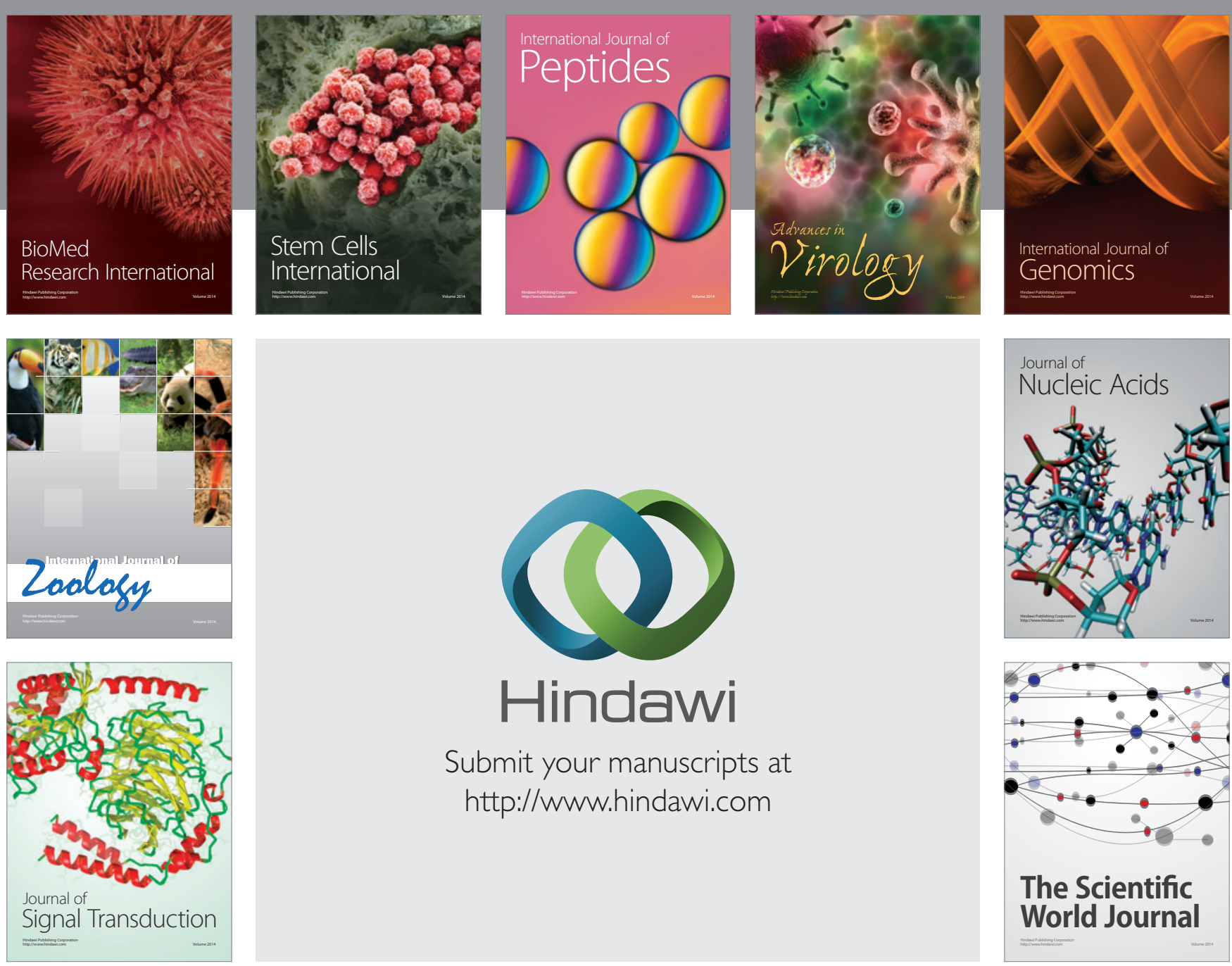

Submit your manuscripts at

http://www.hindawi.com
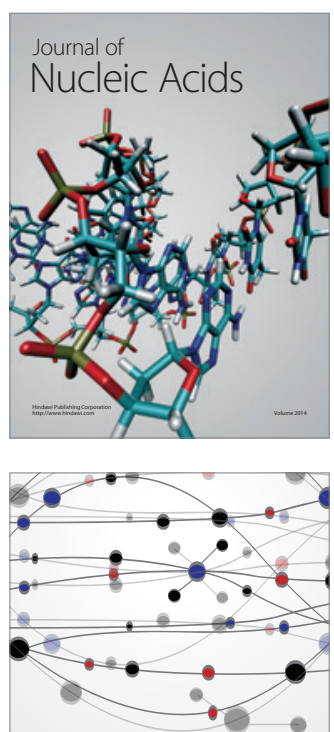

The Scientific World Journal
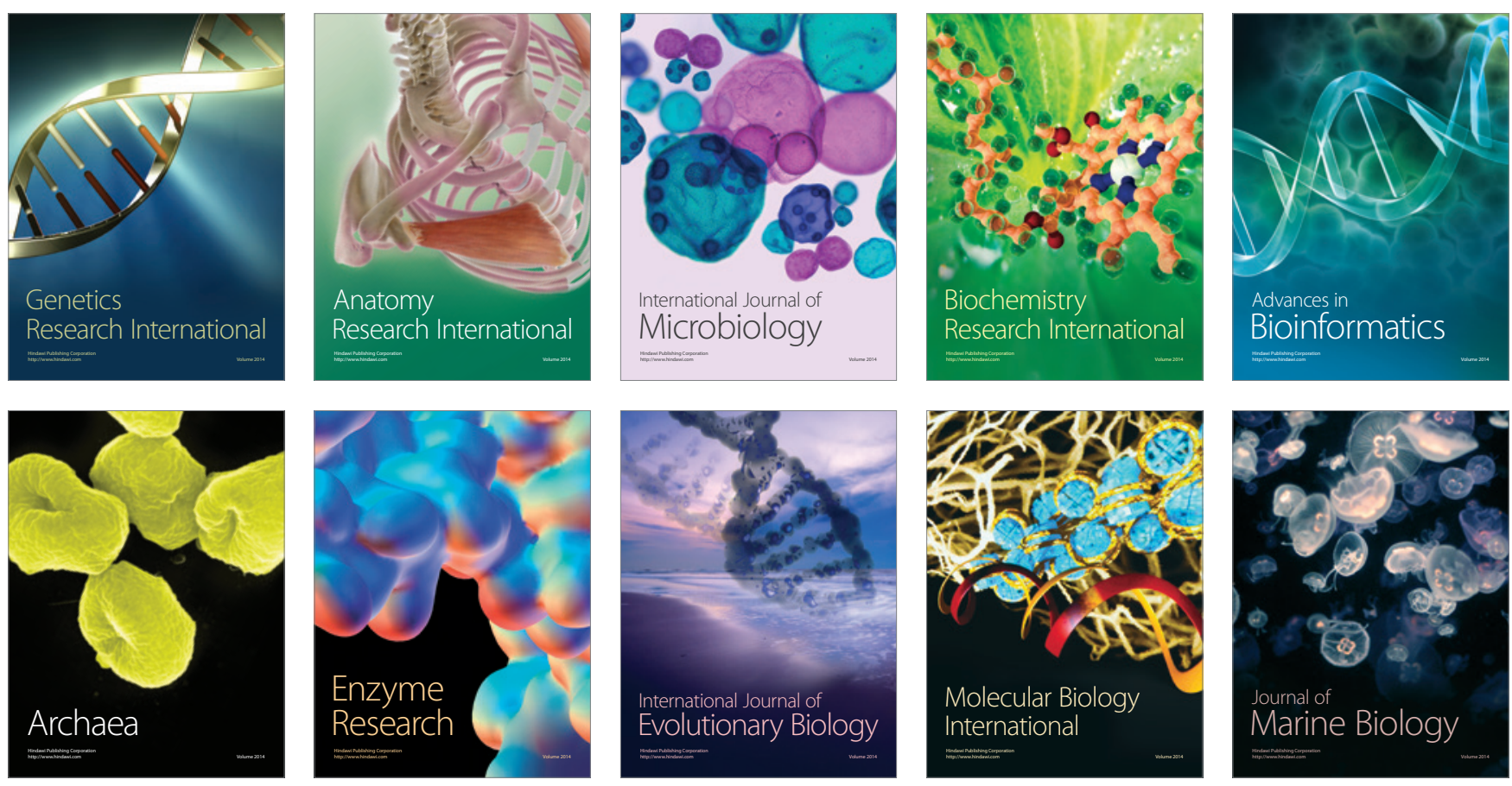